\title{
Left ventricular clefts - incidental finding or pathologic sign of Wilson's disease?
}

\author{
Kun Zhang ${ }^{1,2,6^{*}}$ (D), Ulrike Reuner ${ }^{3}$, Marie Weidauer ${ }^{4}$, Uwe Speiser ${ }^{4}$, Karim Ibrahim ${ }^{5}$, Marian Christoph ${ }^{5}$, \\ Frank R. Heinzel ${ }^{1,6}$, Burkert Pieske ${ }^{1,2,6}$, Felix M. Heidrich ${ }^{4}$ and Silvio Quick ${ }^{5}$
}

\begin{abstract}
Background: Wilson's disease is an inherited autosomal recessive multi-systemic disorder characterized by reduced excretion and consequently excessive accumulation of copper in different organs, such as the heart.

Results: In a prospective controlled trial, which is the largest to date, we evaluated 61 patients with Wilson's disease, age- and sex-matched to 61 healthy patients, for cardiac manifestation using cardiac magnetic resonance imaging. Patients were under stable disease and had no signs of heart failure at the time of examination. We detected a left ventricular cleft, an invagination penetrating more than $50 \%$ wall thickness of the adjoining compact myocardium in diastole, in $20 \%$ of the patients (12 out of 61 ) compared to $5 \%$ among control patients (3 out of $61, p=0.013$. No correlation between the incidence of cleft and a certain genotype of Wilson's disease was found. All described cases were incidental findings and none of the patients showed other signs of cardiac involvement.

Conclusions: To conclude, the results of this study suggests that the increased occurrence of left ventricular clefts is due to Wilson's disease. Large studies with a long observation period are needed for further evaluation.
\end{abstract}

Keywords: Wilson's disease, Cardiac magnetic resonance imaging, Left ventricular cleft

Wilson's disease is an inherited autosomal recessive multi-systemic disorder characterized by reduced excretion and consequently excessive accumulation of copper in different organs. Cardiac involvement has been considered to be benign in the past. However, cases of cardiac sudden death and an increased incidence of arrhythmias and heart failure have been reported. Just recently, we have demonstrated that even asymptomatic patients exhibit structural disease and autonomic dysfunction of the heart $[1,2]$.

In a prospective controlled trial, which is the largest to date, we evaluated 61 patients with Wilson's disease for cardiac manifestation. Wilson's disease was diagnosed beforehand by hepatic copper content assessment in liver biopsy specimens and laboratory findings (ceruloplasmin level in serum below the limit of normal and 24

\footnotetext{
* Correspondence: kun.zhang@charite.de

${ }^{1}$ Department of Internal Medicine and Cardiology, Charité -

Universitätsmedizin Berlin, Campus Virchow-Klinikum, Augustenburger Platz

1, 13353 Berlin, Germany

${ }^{2}$ Berlin Institute of Health (BIH), Berlin, Germany

Full list of author information is available at the end of the article
}

h high urinary copper excretion $>100 \mu \mathrm{g} / \mathrm{d}$ ). Patients were under stable disease and had no signs of heart failure at the time of examination. All patients underwent cardiac magnetic resonance imaging (cMRI) and were age- and sex-matched to 61 healthy patients.

Intriguingly, we detected a left ventricular cleft, an invagination penetrating more than $50 \%$ wall thickness of the adjoining compact myocardium in diastole, in $20 \%$ of the patients (12 out of 61) compared to 5\% among control patients ( 3 out of $61, p=0.013$ ). Left ventricular clefts became best visible in the late gadolinium enhancement images and cine sequences in cMRI (Fig. 1, Additional file 1: Video S1). They were located in the septal segments ( 3 out of 12 ), the inferior (4 out of 12), the lateral (3 out of 12) and the anterior wall (2 out of 12). Additionally, real-time $3 \mathrm{D}$ contrast echocardiography was performed, in which an interventricular shunt could be excluded. No correlation between the incidence of cleft and a certain genotype of Wilson's disease was found (Table 1).

Myocardial clefts are congenital abnormalities related to myocardial fiber or fascicle disarray. Congenital 


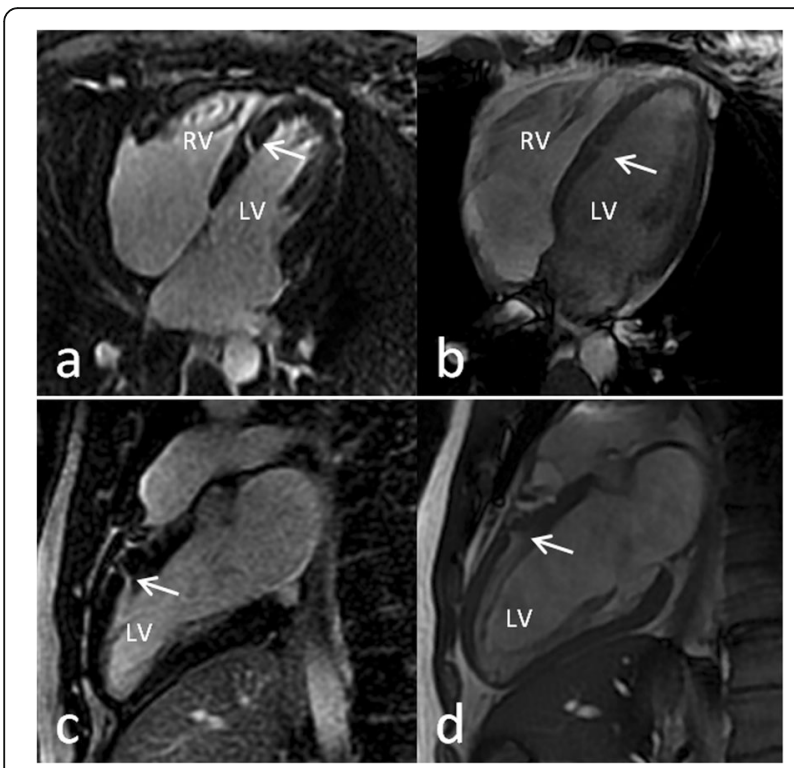

Fig. 1 Representative cardiac magnetic resonance images revealing left ventricular clefts. Late gadolinium enhancement images (a and c) and cine sequences ( $b$ and d) of two patients with Wilson's disease. The arrows show a deep left ventricular cleft in the interventricular septum (patient 1, upper row) and in the anterior wall (patient 2, lower row). LV - left ventricle, RV - right ventricle

Table 1 Chi-quadrat analysis of Wilson's disease mutations and left ventricular clefts

\begin{tabular}{|c|c|c|c|}
\hline Mutation & $\mathrm{n}_{\mathrm{m}}$ & $\mathrm{n}_{\mathrm{c}}$ & $p$-value \\
\hline H1069Q & 24 & 6 & 0.39 \\
\hline A1135Q & 7 & 2 & 0.53 \\
\hline Q1351Stop & 5 & 1 & 0.98 \\
\hline M769V & 1 & 1 & - \\
\hline R969Q & 2 & 2 & - \\
\hline P1352S & 2 & - & - \\
\hline M769H & 5 & - & - \\
\hline R1041W & 2 & - & - \\
\hline S105Stop & 2 & - & - \\
\hline D765N & 2 & - & - \\
\hline H643I & 1 & - & - \\
\hline Q111Stop & 1 & - & - \\
\hline V845S & 1 & - & - \\
\hline G1266R & 1 & - & - \\
\hline P1273L & 1 & - & - \\
\hline G1061E & 1 & - & - \\
\hline T1434 M & 1 & - & - \\
\hline L1325R & 1 & - & - \\
\hline V1282C & 1 & - & - \\
\hline
\end{tabular}

$\mathrm{Nm}$ number of patients with an underlying mutation for Wilson's disease, $n c$ number of patients with left ventricular clefts myocardial clefts or fissures are commonly seen in the basal inferior wall of the left ventricle and the mid to apical segments of the interventricular septum. Petryka et al. studied 686 patients and found these clefts (also called crypts) to be most prevalent in patients with hypertrophic cardiomyopathy (15.6\%), myocarditis (15.3\%), and arterial hypertension (13.6\%). Clefts were also evident, albeit significantly fewer, in $6.7 \%$ of the healthy patients [3]. In other studies, the incidence of clefts in hypertrophic cardiomyopathy was even higher with 61 and $81 \%$, respectively $[4,5]$. They were proposed to be a prephenotypic marker of hypertrophic cardiomyopathy, that means representing early signs of myocardial alterations in patients that carry a gene defect who have not displayed the phenotype yet. The high variance in prevalence among different studies may be due to the variability of cMRI procedures and the interpretation thereof.

The results of our study suggest that clefts are due to the pathology of Wilson's disease. All described cases were incidental findings and none of the patients showed other signs of cardiac involvement. The etiology is a matter of speculation. One hypothesis regarding the pathophysiological mechanism of cleft formation was described by Moon and McKenna who speculate that they may represent a sign of abnormal fetal cardiomorphogenesis [5]. However, it remains unknown how pathological accumulations of copper could support this theory and cause them.

Left ventricular clefts have not been associated to Wilson's disease before. Previous imaging studies on cardiac manifestation are mainly echocardiography based and have not reported on clefts so far. Likewise, in none of our 12 patients, echocardiography was able to detect any evidence thereof. Echocardiographic visualization can be challenging, particularly if cleft location does not coincide with standard acquisition planes. Therefore, cMRI seems to be more sensitive in detecting structural abnormalities than routine echocardiography.

To conclude, the results of this study suggests the occurrence of left ventricular clefts in cMRI as an early sign of Wilson's disease in the heart. Large studies with a long observation period are needed for validation. We propose that patients with Wilson's disease receive cMRI as a standard tool to evaluate cardiac manifestation, specifically with a careful search for left ventricular clefts.

\section{Supplementary information}

Supplementary information accompanies this paper at https://doi.org/10. 1186/s13023-019-1238-7.

Additional file 1: Video S1. Video showing interventricular cleft. 


\section{Abbreviation}

cMRI: Cardiac magnetic resonance imaging

\section{Acknowledgements}

Not applicable.

\section{Authors' contributions}

KZ and SQ analyzed and interpreted the data and were major contributors in writing the manuscript. UR, MW, US, KI, MC, FRH, BP and FMH took part in conducting the study. All authors read and approved the final manuscript.

\section{Funding}

None.

\section{Availability of data and materials}

The datasets used and/or analyzed during the current study are available from the corresponding author on reasonable request.

\section{Ethics approval and consent to participate}

This study was approved by the local ethics committee. Written informed consent was obtained from all participants. The study protocol conforms to the ethical guidelines of the 1975 Declaration of Helsinki.

\section{Consent for publication}

Not applicable.

\section{Competing interests}

The authors declare that they have no competing interests.

\section{Author details}

'Department of Internal Medicine and Cardiology, Charité -

Universitätsmedizin Berlin, Campus Virchow-Klinikum, Augustenburger Platz 1, 13353 Berlin, Germany. ${ }^{2}$ Berlin Institute of Health (BIH), Berlin, Germany. ${ }^{3}$ Department of Neurology, Technische Universität Dresden, University Hospital, Dresden, Germany. ${ }^{4}$ Technische Universität Dresden, Heart Center, University Hospital, Clinic of Internal Medicine and Cardiology, Dresden, Germany. ${ }^{5}$ Department of Cardiology, Technische Universität Dresden, Klinikum Chemnitz, Chemnitz, Germany. ${ }^{6}$ DZHK (German Centre for Cardiovascular Research), partner site Berlin, Berlin, Germany.

Received: 21 August 2019 Accepted: 22 October 2019

Published online: 07 November 2019

\section{References}

1. Quick S, Weidauer M, Heidrich FM, Sveric K, Reichmann H, Ibrahim K, et al. Cardiac manifestation of Wilson's disease. J Am Coll Cardiol. 2018;72(22): 2808-9.

2. Quick S, Reuner U, Weidauer M, Hempel C, Heidrich FM, Mues $C$, et al. Cardiac and autonomic function in patients with Wilson's disease. Orphanet J Rare Dis. 2019;14(1):22.

3. Petryka J, Baksi AJ, Prasad SK, Pennell DJ, Kilner PJ. Prevalence of inferobasal myocardial crypts among patients referred for cardiovascular magnetic resonance. Circ Cardiovasc Imaging. 2014;7(2):259-64.

4. Germans T, Wilde AA, Dijkmans PA, Chai W, Kamp O, Pinto YM, et al. Structural abnormalities of the inferoseptal left ventricular wall detected by cardiac magnetic resonance imaging in carriers of hypertrophic cardiomyopathy mutations. J Am Coll Cardiol. 2006;48(12):2518-23.

5. Moon JC, McKenna WJ. Myocardial crypts: a prephenotypic marker of hypertrophic cardiomyopathy? Circ Cardiovasc Imaging. 2012;5(4):431-2.

\section{Publisher's Note}

Springer Nature remains neutral with regard to jurisdictional claims in published maps and institutional affiliations.

Ready to submit your research? Choose BMC and benefit from:

- fast, convenient online submission

- thorough peer review by experienced researchers in your field

- rapid publication on acceptance

- support for research data, including large and complex data types

- gold Open Access which fosters wider collaboration and increased citations

- maximum visibility for your research: over $100 \mathrm{M}$ website views per year

At BMC, research is always in progress.

Learn more biomedcentral.com/submissions 